\title{
REDEFININDO COMPETÊNCIA TRADUTÓRIA EM UMA ERA ELETRÔNICA. EM DEFESA DE UMA ABORDAGEM MINIMALISTA
}

\author{
Anthony Pym \\ Universitat Rovira i Virgili, Tarragona/ Espanha \\ anthony.pym@urv.net
}

Resumo: Desde os anos setenta a noção de "competência tradutória" foi vista, pelo menos, como: 1) um modo de bilingüismo aberto à análise lingüística; 2) uma questão de demanda de mercado, determinada por mudanças históricas e sociais extremas; 3 ) uma competência multicomponencial envolvendo grupos de habilidades que são lingüísticas, culturais, tecnológicas e profissionais; e 4) uma "supercompetência", que estaria de alguma maneira acima do resto. A tendência geral entre teóricos foi ampliar o modelo multicomponencial para incorporar novas habilidades e proficiências ao campo do treinamento do tradutor. Pode-se esperar que essa tendência continue com o uso crescente de ferramentas eletrônicas. Discutimos aqui, porém, que as expansões multicomponenciais da competência são, em parte, fundamentadas em interesses institucionais e que, conceitualmente, são falhas no sentido de que sempre estarão um ou dois passos atrás das demandas do mercado. Por outro lado, um conceito minimalista simples de competência tradutória, baseado na produção e subseqüente eliminação de alternativas, pode ajudar a orientar o treinamento do tradutor em tempos de rápida mudança tecnológica e profissional.

Palavras-chave: competência tradutória, treinamento do tradutor, processo de tradução, habilidades de tradução.

Abstract: Since the 1970s the notion of "translation competence" has been viewed as at least 1) a mode of bilingualism, open to linguistic analysis, 2) 
a question of market demands, given to extreme historical and social change, 3) a multicomponent competence, involving sets of skills that are linguistic, cultural, technological and professional, and 4) a "supercompetence" that would somehow stand above the rest. The general trend among theorists has been to expand the multicomponent model so as to bring new skills and proficiencies into the field of translator training. This trend may be expected to continue with the increasing use of electronic tools. Here it is argued, however, that the multicomponential expansions of competence are partly grounded in institutional interests and are conceptually flawed in that they will always be one or two steps behind market demands. On the other hand, a simple minimalist concept of translation competence, based on the production then elimination of alternatives, can help orient translator training in times of rapid technological and professional change.

Keywords : translation competence, translator training, translation process, translation skills

Meus alunos estão reclamando, de novo. Em nosso curso de Tradução Avançada, não estamos realmente traduzindo, dizem eles. Mas, respondo depressa, aprendemos a usar ferramentas de revisão e comentários no Word; descobrimos alguns bons truques para buscas na Internet; aprendemos sobre HTML; podemos fazer a criação e a localização sites bastante sofisticados; podemos fazer coisas maravilhosas com memórias de tradução... e são coisas como essas que o mercado de trabalho está procurando ativamente. Tudo isso, eu insisto, é parte integrante do ato tradutório hoje em dia. Não, alguns ainda respondem, o que nós queremos é listas de falsos cognatos, estratégias de modulação, todos os truques lingüísticos, mais alguma prática em uns poucos textos realmente especializados... e isso, meus alunos mais críticos acreditam, é a essência invariável do que deveriam aprender na aula de tradução.

Como solucionar esse conflito? Uma proposta prática será dada perto do final deste artigo. Mais interessante, entretanto, é o problema teórico e pedagógico geral envolvido. Esses estudantes e eu temos uma discordância fundamental sobre o que é traduzir e sobre como isso deveria ser ensinado. Discordamos sobre a natureza da competência tradutória. Como professor, quero transmitir todas as habilidades requisitadas pelo mercado de trabalho. E, contu- 
do, eu admito, meus alunos mais críticos têm razão no seguinte: ao se inscreverem em tradução, esperam traduzir, no nível básico de uma interseção entre idiomas, coisas da lingüística. Então a competência tradutória é realmente a mesma de sempre (como aqueles alunos esperam)? Ou ela mudou radicalmente na era das ferramentas eletrônicas (como a natureza de meu curso sugere)?

\section{Quatro noções de competência tradutória}

O que é competência tradutória? Para não reinventar a roda, partiremos de algumas páginas escritas pelo estudioso alemão Wolfram Wilss em 1976, em algum lugar próximo ao início institucionalizado dos Estudos da Tradução. Wilss diz quatro coisas bastante diferentes sobre competência tradutória.

Primeiro ele nota com certo pesar que a incipiente Ciência Aplicada da Tradução

não pode fornecer uma resposta satisfatória à questão da qualificação profissional mínima de um tradutor, acima de tudo porque a competência tradutória como qualificação uniforme para o trabalho é, para todos os efeitos, inexistente e provavelmente também indefinível. (1976: 119)

Logo, "competência" não pode ser confundida com questões de qualificação profissional, não importa o quanto professores como eu se preocupem com o treinamento dos alunos para o trabalho. Isso faz sentido, já que as qualificações mudam com a tecnologia e com as demandas sociais, introduzindo variáveis históricas que são simplesmente numerosas demais para as eternas generalidades de uma ciência. Então, outra vez, se a ciência deve ajudar a treinar tradutores e se tradutores serão empregados pelas competências adquiridas, certamente não podemos apenas permanecer calados sobre o que o mercado requer. 
O segundo ponto de Wilss contrasta totalmente com o primeiro. Agora, aparentemente, o tradutor necessita ter oito "faixas de competência", cada uma com duas subcategorias (uma para cada idioma envolvido), totalizando dezesseis compartimentos para todas as coisas que os aprendizes deveriam aprender a fazer com o idioma. Por que dezesseis? Por que não 127? Ou apenas sete? Nenhuma razão é fornecida para a seleção das categorias, o que não tem peso maior que suas origens na lingüística mais básica. Contudo a idéia "multicomponencial" foi anunciada e poderia ser potencialmente ampliada e reduzida à vontade.

A terceira idéia parece então restringir essa expansão: Wilss percebe que "ambas subcompetências [as dos dois idiomas envolvidos] estão em relação complementar entre si e, juntas, constituem a base da competência tradutória" (120). Isso é o mesmo que dizer $1+1=2$, onde a competência tradutória é a soma do que o tradutor sabe em dois idiomas. Pelo menos isso deixa os números mais claros.

Porém, como se coisas já não estivessem confusas o bastante, o quarto e último ponto de Wilss parece dizer algo bem diferente. Agora a competência tradutória é "claramente distinta das quatro habilidades monolíngües tradicionais: escuta, fala, leitura e escrita", tornando-se assim algo como uma "supercompetência" (120).

Assim, encontramos no primeiro Wilss uma reivindicação de não haver algo como uma competência tradutória, depois uma definição multicomponencial da mesma, um modelo somatório de duas línguas e, por fim, a menção a uma misteriosa metacompetência, tudo isso em duas páginas! Qual dessas idéias sairia vitoriosa?

Aqui esboçaremos brevemente as aventuras e os avatares dessas idéias desde 1970. Nossa história deve então explicar as razões por trás de nossa própria definição proposta. 


\section{Competência como somatório de competências lingüísticas}

Comecemos com a idéia de $1+1$, que parece intuitivamente fazer sentido. Em The Science of Translation (1982), Wilss mais ou menos se prende ao conceito de somatório de línguas: o tradutor "tem que ter uma competência analítica de textos na LO [língua original] e uma competência reprodutiva de textos na LT [língua da tradução]" (118). Os tradutores são pessoas competentes em dois idiomas, e seu trabalho envolve claramente reunir essas duas competências. Isso é mais ou menos o que encontramos no posicionamento inicial de Brian Harris, sobre ser a competência tradutória algo que crianças bilíngües desenvolvem quando realizam "tradução natural” (Harris 1977; Harris e Sherwood 1978). Bilíngües começariam a traduzir para si próprios, depois para os outros, e essa progressão deveria nos revelar o que todos os tradutores fazem. Os lingüistas do bilingüismo poderiam, assim, tornarem-se também lingüistas da tradução, sem haver necessidade de se desenvolver uma disciplina acadêmica separada. Seguindo a mesma linha, Werner Koller descreveu a competência tradutória como sendo "a habilidade para reunir [verbinden] as competências lingüísticas conquistadas em dois idiomas" (1979: 40)ํ․ Michel Ballard contestou que os segredos de ensinar tradução estão no "uso de dois idiomas ao mesmo tempo" (1984: 17), pretextando uma vez mais que o nível da prática tradutória é basicamente um somatório de línguas. Esse tipo de competência parece uma versão abstrata de bilingüismo, basicamente afinada com o pensamento de Harris.

Todas essas descrições parecem óbvias o bastante. Porém, para quem buscava independência institucional, um lugar separado para treinar os tradutores e pensar sobre a tradução, o simples somatório não era uma forma feliz de pensar. Isso manteve os Estudos da Tradução dentro de Lingüística Aplicada, e o Treinamento do Tradutor dentro de escolas de idiomas ou departamentos de Línguas Modernas. A tendência dominante nas políticas acadêmicas, pelo 
menos nos anos setenta e oitenta (as datas de nossas citações), era buscar maior poder tornando-se independente. Pouquíssimas vozes se levantaram contra essa independência idealizada. A idéia de somatório teve, por conseguinte, vida curta como tal, embora seu naturalismo subjacente (a "tradução natural" de Harris) também viesse a informar modelos baseados na lingüística cognitiva.

\section{Competência como nada disso}

Por que Wilss não quis tratar a competência como uma "qualificação profissional mínima?" Uma razão certamente reside na natureza da ciência eterna que ele estava tentando construir. Outra, no fato de que o termo "competência" denotava um conceito fundamental em lingüística, que talvez fosse a disciplina dominante nas ciências humanas da época. Aquele conceito estava tão distante dos mercados históricos quanto se poderia imaginar. Chomsky havia distinguido entre "competência" e "desempenho", o que poderia ser comparado muito livremente à distinção de Saussure entre langue e parole. Logo, o termo "competência tradutória" deveria referir-se a um tipo de conhecimento sistêmico subjacente ao real desempenho dos tradutores, da mesma forma que uma gramática está por trás do uso da fala. O primeiro Koller (1979: 185), não obstante, sustentou ser a competência tradutória qualitativamente diferente da competência lingüística, da mesma forma que a fala (parole) é diferente da língua (langue), o que colocaria a competência tradutória, na realidade, no lado do "desempenho" chomskiano. Quer dizer, esse tipo específico de competência concernia o uso real da linguagem, não importa quão firmemente a lingüística chomskiana tivesse ancorado o termo "competência" no outro lado da divisa. Essa foi a estratégia de Koller para separar Estudos da Tradução e Lingüística Contrastiva, ganhando, assim, espaço institucional. Infelizmente, Saussure (1974: 19ff.) argumentara que nada de científico poderia ser dito sobre a parole, e 
Chomsky (1965) removera completamente a tradução do escopo de suas ambições. Dizer que havia uma competência dentro do desempenho ou um sistema dentro da parole era embarcar em paradoxos sobre os quais a ciência lingüística simplesmente não queria cogitar.

Como poderia o paradoxo de uma competência baseada em desempenho ser solucionado? No princípio, isso significava seguir uma lingüística não-chomskiana, o que normalmente envolvia a adoção de uma terminologia alternativa. Em 1988, Wilss estava fazendo psicolingüística, invocando uma abordagem cognitiva na qual a competência tradutória era um somatório de conhecimento declarativo e "conhecimento de processos de tradução" (übersetzungsprozessuale Wissen), embora a natureza destes estivesse longe de ser clara. Em 1989, encontramos Wilss usando o vocabulário alternativo de "habilidades" (Fertigkeiten); em 1992 ele estava prestes a abandonar de vez a "competência" e substituíla pela mais pedagógica "proficiência" (1992: 185). Lörscher, escrevendo em termos de psicolingüística em 1991, declarou de modo semelhante não precisar de "competência" nenhuma; ele pensava que, de alguma maneira, o conceito não estava relacionado a processos reais de tradução (1991: 2), o que significava que ele poderia sobreviver feliz com uma conversa de "estratégias" sendo usadas para resolver problemas. Nem havia qualquer problema terminológico específico quando um Wilss ainda mais maduro (1996: 4) recorreu à sociolingüística para descrever o uso de idiomas como "compartilhamento de código", de modo que a tradução se torna um caso de "troca de código" (um insight valioso que parece não ter convencido mais ninguém). Shreve (1997: 130) baseava-se na lingüística cognitiva, descrevendo competências de idioma como "habilidades de mapeamento", permitindo assim que a competência tradutória se tornasse o processo pelo qual um tradutor podia “mapear mapas”. Risku (1998) nomeou seu o objeto como "competência translatória", porém, imediatamente ela mudou para o discurso de "perícia" (expertise), estabelecido como um termo fundamental desde meados dos anos 80 (cf. Holz-Mänttäri, 1984). Schäffner e Adab (2000: x) explicitamente aceitaram que aquela 
"competência" envolvia uma grande quantidade de outros termos; eles, na verdade, propuseram que fosse seja aceita como "um termo de cobertura e conceito cumulativo para a habilidade global de desempenho que parece tão difícil definir" (ibid.). Mas, note a redução quase irrefletida à "habilidade de desempenho", como se nunca tivesse havido um paradoxo a solucionar. $\mathrm{Na}$ realidade, na maioria desses autores, incluindo os reunidos no volume Developing Translation Competence, editado por Schäffner e Adab (2000), encontramos o termo "competência" simplesmente sendo jogado para lá e para cá, com o referente mais significativo tornando-se então qualquer outra coisa, algum outro termo.

Será que os problemas da competência tradutória seriam resolvidos simplesmente pelo não uso da palavra? Sim e não. Nos anos iniciais, fazia sentido buscar palavras alternativas, ao menos para evitar as restrições de Chomsky. Porém, o abandono de "competência” mostrou-se desnecessário no final das contas. A própria natureza da lingüística vinha mudando cada vez mais, com atenção crescente para a análise do discurso, a lingüística textual, a pragmática, a psicolingüística e a sociolingüística, todas elas requerendo de modo semelhante um posicionamento da "competência" em algum lugar mais próximo do lado do desempenho. Os movimentos feitos pelos teóricos da tradução estavam na maior parte seguindo as tendências da própria lingüística, embora com um nível muito mais restrito de consciência teórica.

\section{Competência como multicomponencial}

Ao lado dessa busca por outras palavras, a idéia multicomponencial estava acumulando uma história bem rica, muito da qual com base na pesquisa em aquisição de segunda-língua e, de modo semelhante, beneficiando-se de muitas tendências "em nível de desempenho" na lingüística. Em 1991 Roger Bell descreveu a competência do tradutor como um enorme somatório: conhecimento 
da língua da tradução, conhecimento do tipo de texto, conhecimento da língua original, da área do assunto ("mundo-real”), conhecimento contrastivo e, ainda, habilidades de decodificação e habilidades de codificação resumidas como "competência comunicativa" (cobrindo gramática, sociolingüística e discurso). Virtualmente tudo sobre o que qualquer tipo de lingüística queria falar foi jogado na sopa. Christiane Nord (1991: 165-166), valendo-se de Bausch (1977), distingue o tipo de competência necessário aos tradutores e a competência que a prática tradutória poderia desenvolver na aula de idiomas (consciência de estruturas contrastivas e habilidades como o uso efetivo de dicionários), mas ela, não obstante, recusase a excluir quaisquer desses aspectos do seu modelo pedagógico. Essa abordagem geral poderia gerar algumas formulações relativamente simples. Por exemplo, Neubert (1994: 412) oferece "competência de idioma", "competência de assunto" e "competência de transferência" como os três componentes principais. Lee-Jahnke reduz o "conhecimento objetivo" do tradutor a três títulos diferentes: língua materna, língua estrangeira e "bagagem sociocultural" (1997: 178). E, contudo, uma vez que se chega a terceiros termos como esses, vários labirintos são abertos, e não há virtualmente qualquer limite para o número de coisas que podem ser necessárias a um tradutor. Hatim e Mason (1997: 204-206), trabalhando a partir de Bachman (1990), apresentam uma competência tradicional de três partes herdada da lingüística (processamento de TO, transferência, processamento de TT) e, em seguida, nomeiam um tanto de habilidades para cada um desses títulos. Hewson (1995) adiciona algo chamado "elementos culturais e profissionais" (108), onde a parte "profissional" refere-se a "remuneração [...], acesso a dicionários e a bancos de dados adequados e uso dos mesmos, acesso a material equivalente no segundo idioma, conhecimento prático de processadores de texto e periféricos, e assim por diante" (ibid.). Hurtado (1996) divide a competência tradutória em lingüística, extralingüística, textual (compreensão e produção), "habilidades profissionais" gerais e "competência de transferência" (competencia translatoria, depois chamada competencia de 
transferencia), descrita harrisianamente como "uma predisposição de trocar de uma língua para outra sem interferências" (1996: 34). Em 1999 (4344, 245-246), encontramos o mesmo autor adicionando coisas chamadas "competência estratégica" (já que estratégias estavam na moda) e "competência psicofisiológica" (sem dúvida, para ter certeza de que todas as bases foram abrangidas). Presas (1997) leva em conta competências centrais quanto a idiomas (recepção do TO, produção de um rascunho do TT, produção do TT final), depois acrescenta uma série de "competências periféricas", que incluem o uso de dicionários, a documentação, o conhecimento da área, o uso de instruções e ferramentas tecnológicas. Em um texto posterior (1998), o mesmo autor adiciona "configuração adequada de memória [de tradução]", "flexibilidade na troca de código" e "controle de interferência" como componentes de uma competência especificamente "pré-tradutória" . Isso permite, na verdade, que certos modos de ensino de línguas se tornem parte do treinamento do tradutor, redefinindo limites institucionais chave (cf. Mayoral, 2001: 125). Beeby (1996, 2000) segue uma tendência semelhante de multiplicação, detalhando seis subcompetências, todas se mesclando dentro da tal competência tradutória, cada uma das quais com até quatro ou cinco subcomponentes. Kautz (2000: 20) adota uma abordagem ligeiramente diferente, reconhecendo que os tradutores precisam de conhecimento de dois idiomas, conhecimento de mundo e de campo, teorias e métodos de tradução e, então, algo mais, chamado "competência translatória" (translatorische Kompetenz), que engloba habilidades na análise das instruções do cliente e do TO, estratégias de tradução, apresentação do TT (inclusive diagramação), documentação, terminologia e conhecimento da prática profissional do tradutor. Verdadeiramente notável aqui é o quanto demorou para que as definições de competência incluíssem referência às instruções do cliente (Auftrag, client's brief, instructions), um ponto chave na Skopostheorie de língua alemã desde 1984. Em Fraser (2000), encontramos um maior desenvolvimento dessa linha, segundo a qual 
os tradutores autônomos descrevem sua competência em termos de "levantamento detalhado de instruções e recursos para o trabalho em mãos, junto com feedback e avaliação da tradução realizada, em termos de como ela alcança seu propósito ou satisfaz às necessidades de seus leitores" (60), tudo isso soando mais como simples desideratos do que como um tipo estrito de competência. Mayoral (2001: 109) insiste em componentes que incluem "bom senso (acima de tudo), curiosidade, habilidade para se comunicar, capacidade de autocrítica, meticulosidade, habilidade para sintetizar, etc." Algo mais? Em Becoming a Translator, de Douglas Robinson (1997), encontramos atenção séria às necessidades do mundo real, como boa velocidade de digitação, grupos de discussão na Internet e trabalho com computador em um quarto à temperatura certa (sic). Quanto a esse assunto, Pym (1992) chama atenção para os benefícios estratégicos de se usar um bom terno e gravata, especialmente nos dias em que você está de ressaca. E o onipresente Wilss (1996: 11), com a ironia dos sábios, reconhece que a pontualidade é um requisito essencial de tradutores ("fast is smart"), junto com a igualmente eficiente "redução de complexidade", tudo isso podendo conduzir a qualquer lugar.

Por que o fator tempo não foi mencionado em quaisquer das formulações anteriores de Wilss? Ainda, por que essas várias necessidades estavam ausentes de quase todas as definições iniciais? E por que as listas de componentes parece ter crescido tanto ao longo dos anos? Talvez porque os primeiros estudiosos estivessem pensando em termos de lingüística e de estudantes, e não em termos de como os tradutores trabalham no mundo (tal era a exclusão explícita em Wilss). Talvez porque os estudiosos simplesmente gostam de falar sobre um tanto de coisas. Ou são eles apenas intelectualmente ineptos, dada a produção de listas falsamente oficiais? Talvez, também, a explosão de componentes tenha seguido a evolução dos Estudos da Tradução como uma "interdisciplina", não mais restringida por qualquer forma de lingüística. Como um grande número de disciplinas vizinhas pode ser utilizado, um gran- 
de número de coisas pode ser incluído sob o rótulo "competência tradutória". E talvez, mais importante ainda, a própria evolução da profissão tenha fragmentado radicalmente a gama de atividades envolvidas. Nos anos setenta, tradutores basicamente traduziam. Em nossa própria era, tradutores são obrigados a fazer muito mais: documentação, terminologia, reescritura e a série de atividades associadas à indústria da localização. Por isso focalizamos ferramentas eletrônicas em nossas aulas. Talvez, na base, a explosão de componentes tenha apenas acompanhado a profissão até uma era mais integralmente eletrônica. A dificuldade que Wilss havia insinuado em 1976 (que as exigências de mercado nesse campo são muito históricas para serem sistematizadas como uma competência) foi comprovada pela própria história: quanto mais os estudiosos observam, mais coisas inserem, sem limites visíveis.

As deficiências metodológicas dos modelos multicomponenciais são bastante óbvias. Waddington (2000: 135) lista três: 1) é difícil saber quantos componentes deveriam fazer parte da competência tradutória; 2) as definições tendem a abarcar uma competência ideal e são, por isso, incompletas sem um modelo do processo de aprendizagem (cf. Toury 1995: 238); e 3) há uma carência de evidência empírica para a maioria dos modelos disponíveis. Embora concordemos com as primeiras duas reclamações, não concordamos necessariamente com a terceira ${ }^{2}$. E poderíamos adicionar uma quarta e ampla reclamação: por mais inocentemente descritivos que possam parecer, os modelos multicomponenciais estão carregados não apenas de suposições sobre o que é a tradução e como deveria ser ensinada, mas especialmente sobre o nível no qual o ensino específico é necessário e durante quantos anos. Inevitavelmente, alimentam perfis profissionais complexos ("um bom tradutor precisa de A, B e C..."); destacam assim não apenas um tradutor ideal transcendental que não tem lugar no mercado fragmentado, mas também os programas de treinamento interdisciplinar de longa duração que pretendem produzir tais coisas (principalmente programas universitários de graduação com duração de quatro ou 
cinco anos). Na maioria das vezes, os complexos modelos de competência coincidem mais ou menos com as coisas ensinadas nas instituições onde os teóricos trabalham. Que surpresa! Sem dúvida, a multicomponencialidade acompanhou o desenvolvimento fragmentário da profissão; é obviamente uma resposta à interdisciplinaridade e ao rompimento com a lingüística; mas, institucionalmente, opera como uma defesa política de um certo modelo de treinamento do tradutor. E aquele modelo não é o único, nem necessariamente o melhor.

\section{Competência como uma só coisa}

Wilss, devemos lembrar, também sugeriu que a competência tradutória era um tipo de "supercompetência", além e acima dos vários componentes lingüísticos. Essa noção bastante vaga foi desenvolvida em definições minimalista posteriores. Gideon Toury (1984, 1986), polemizando naquela época com Harris sobre a natureza da "tradução natural", seguia a mesma direção quando levantou a hipótese uma "competência de transferência" específica que não era uma simples sobreposição de competências em dois idiomas: requeria modos particulares de socialização (cf. Toury 1995: 246, 250). Mas, qual era a natureza exata desse terceiro e necessário termo? Hans P. Krings (1986) produziu uma tipologia de problemas de tradução na qual alguns deles concerniam TO, outros tinham a ver com habilidades do idioma de tradução e um terceiro grupo envolvia questões estritamente interlinguais. Esse terceiro grupo foi então rotulado "problemas de competência tradutória" (112-171), também descrito como "problemas de recepção-produção" (144-152). De forma semelhante, quando Werner Koller reafirmou sua posição quanto à competência tradutória em 1992, ele enfatizou que "não era simplesmente mais competência de idioma [...], mas também a criatividade envolvida em achar equivalentes e selecionar dentre eles e na cada vez mais necessária [habilidade 
de] produção de texto" (1992: 20). Shreve estaria dizendo a mesma coisa quando fala sobre a necessidade de "mapear mapas" (1997: 130). E nós vimos idéias semelhantes aparecendo em vários lugares dentro das definições multicomponenciais, embora a pluralidade de outros componentes tendesse a esconder qualquer especificidade que pudesse pertencer a esta. As várias palavras para o terceiro (ou quarto, ou quinto!) termo poderiam estar nomeando a mesma coisa, a especificidade singular da tradução. Contudo, ainda não há qualquer consenso visível nesse ponto.

Dado o fracasso inerente do modelo multicomponencial em acompanhar a mudança histórica, reflexões sérias deveriam ser dedicadas agora à abordagem minimalista da "supercompetência". Isso significa aceitar que não há nenhuma definição clara de todas as coisas que os tradutores precisam saber nem daquelas para as quais serão chamados a fazer. Muito menos há qualquer razão para supor que a competência é de todo sistemática, como as regras gramaticais e fonológicas que forneciam o conteúdo arquetípico do termo. Precisamos é, além de listas e de sistemas, de um conceito que possa definir a tradução e nada mais que a tradução. Só então podemos orientar o resto.

Estudos empíricos podem ajudar com esse problema? É difícil imaginar qual tipo de plano de pesquisa pode determinar a especificidade da tradução. Empirismo pode significar simplesmente perguntar a pessoas diferentes o que pensam que a competência tradutória deveria ser, mas isso não garante que os vários grupos usam os termos fundamentais ("tradução" e "competência") de forma sequer parecida (cf. Fraser 2000). Quer gostemos ou não, os termos têm que ser definidos primeiro.

Para um exemplo de possível empirismo, consideremos brevemente a pesquisa inicial mencionada acima. Krings (1986) estudou seis traduções realizadas por estudantes alemães que trabalham o francês (sua primeira língua estrangeira, ou L2). Os problemas que encontraram foram categorizados como tendo a ver ou com o conhecimento da língua francesa ou com processos interlinguais, 
estes sendo descritos como relativos à "competência tradutória", o que parece ser aquilo que procuramos. Porém, descobriu-se que só $6,5 \%$ dos problemas realmente se enquadravam nessa segunda categoria (eles foram classificados como tal quando fatores de L2 pareciam não estar envolvidos). Em sua crítica a essa pesquisa, Löscher (1991: 96) indica corretamente que a pequena porcentagem é não apenas difícil de distinguir do resto, mas que a própria distinção não tinha nenhuma realidade psicológica para os sujeitos, uma vez que não havia evidência de que os alunos pensassem nesses problemas de modos notadamente diferentes. Pode-se apenas concluir que Krings levou as categorias a se relacionarem a dados, em vez de derivar seu modelo de competência tradutória de baixo para cima a partir dos próprios dados. E isso, sugerimos, é necessariamente assim.

Mais atrativo pareceria o trabalho de Campbell (1992) sobre as traduções de 41 estudantes do mesmo texto a partir do árabe como L2. Campbell considera ter a competência tradutória dois componentes bastante diferentes: "disposição", cobrindo qualidades psicológicas como capacidade de assumir riscos e persistência, e "proficiência", o que inclui "certas habilidades bilíngües e tem uma dimensão desenvolvimentista". Isso é interessante porque a parte da "disposição" responderia pela razão por que tradutores diferentes trabalham de formas diferentes (cf. a "criatividade" mencionada por Koller em 1992), enquanto que a "proficiência" se referiria a um tipo mais estático de conhecimento (codificação léxica, competência global da LT e palavras de conteúdo/função). Uma vez mais, é difícil acreditar que os dados forneceriam essas categorias caso o investigador não tivesse a intenção de combinar psicolingüística com estudos em bilingüismo. A posição disciplinar estava lá antes da pesquisa. Porém aqui, sob o título muito vago de "disposição", parecemos estar chegando a algo bastante mais concreto que poderia pertencer à tradução e nada além da tradução.

A pesquisa empírica pode ser útil? Indubitavelmente, sim. Nossos modelos e nossa definição devem poder entender os diversos 
dados em muitos níveis (traduções, erros, dúvidas, expectativas, pressões de tempo, etc.) e deveriam idealmente fazê-lo de modo que os modelos e definições fossem falsificáveis (esse aspecto, infelizmente, tem estado ausente). Então, novamente, não, o passo fundamental reside na tarefa intelectual de demarcar o campo de estudo em primeiro lugar. E aí, na produção de uma definição, o problema não é só responder pelos dados; é também chegar a algum tipo de consenso entre a comunidade de tradução, ela deveria orientar a pesquisa e deveria, idealmente, focalizar o treinamento. Em tudo isso, uma definição pode parecer tão científica quanto você quiser, mas nunca pode permanecer realmente neutra. Como veremos agora.

\section{Uma definição minimalista}

Como uma atividade interpessoal que trabalha textos (de qualquer extensão ou estado fragmentário), o treinamento de tradutores envolve a criação das seguintes competências funcionais duplas (cf. Pym 1991):

- habilidade para gerar um grupo de mais de um texto traduzido viável (TT1, TT2... TTn) para um texto de fonte pertinente (TO);

- habilidade para selecionar apenas um TT viável desse grupo, depressa e com confiança justificada.

Nós propomos que, juntas, essas duas habilidades formam uma competência tradutória específica; a união delas diz respeito à tradução e somente à tradução. Não pode haver dúvida de que os tradutores precisam saber uma boa quantidade de gramática, retórica, terminologia, informática, prática de Internet, conhecimento 
de mundo, cooperação, trabalho em equipe, estratégias para conseguir receber corretamente, e o resto, mas a parte especificamente tradutória da prática não é nem estritamente lingüística nem puramente comercial. É um processo de geração e seleção, um processo de solução de problemas que muitas vezes acontece com aparente automatismo.

Exemplificando como essa solução de problemas pode acontecer, considere a seguinte oração, de um texto que minha classe estava vertendo coletivamente para o inglês:

Los alumnos que hayan estudiado en el extranjero y deseen iniciar estudios en las universidades españolas deberán convalidar u homologar sus estudios.

Tudo correu muito bem com

Students who have studied outside Spain and wish to enter a program at a Spanish university must convalidar or homologar their foreign studies.

Não houve maiores problemas de tradução até nos depararmos com os verbos em negrito. O que os alunos deveriam fazer? Primeiro, alguns geraram fugazes possibilidades usando o mais simples dos princípios: convalidate, talvez, mas, será que existe homologate em inglês? Após alguns segundos de busca na Internet, localizaram textos análogos onde accreditation (credenciamento) é dado como termo geral para o caso. Alguns segundos a mais e eles acharam descrições de como homologación e convalidación são usados em processos burocráticos (basicamente, o primeiro é para certificados e diplomas entendidos como pedaços de papel, e o segundo, para os cursos realmente freqüentados). Mas, como os tradutores fariam para que o termo em inglês desse conta dos dois processos? Tiveram poucas idéias; esse foi mais ou menos o limite 
até onde o lado gerativo da questão (impecavelmente tecnologizado) poderia levá-los. E nada coerente emergiu, até que algumas estratégias redutivas foram levadas em consideração. Depois de algumas perguntas iniciais sobre a natureza e o propósito do texto em questão, os alunos começaram a considerar a posição dos futuros leitores daquele texto, os estudantes estrangeiros. Do que necessitarão esses leitores? Se eles não precisassem de credenciamento, então os dois termos espanhóis seriam supérfluos e poderiam ser combinados em um simples accreditation. E se os leitores precisassem realmente de credenciamento, também precisariam daqueles termos em espanhol, junto com descrições exatas dos processos envolvidos. Assim, as informações do texto na língua original teriam que ser ou reduzidas ou aumentadas, sem qualquer necessidade real de se emparelhar os dois termos espanhóis com dois ingleses. Esse tipo de raciocínio redutivo, impecavelmente pragmático, é talvez a parte da competência tradutória mais difícil de se ensinar.

Nossa definição poderia ser aplicada a muitos níveis e estratégias além desse exemplo, como se pode esperar de uma "supercompetência". Suas virtudes relativas incluem a aplicabilidade a traduções intra e interlinguais, o reconhecimento de que não existe conhecimento fixo neste campo e o fato de se evitar qualquer noção de transferência de significado (traduzir é uma questão de solucionar problemas, não de movimentar significados). O tipo de processos nos quais estamos interessados são, claramente, tanto sociais quanto cognitivos (os alunos acima estavam discutindo o problema da tradução como um grupo). A definição deveria, assim, permitir hipóteses em ambos os níveis, sem presumir qualquer forma de "tradução natural" como aquela que embasou o modelo do somatório de línguas. E mais, a definição recusa qualquer noção de correção imutável, já que os critérios de viabilidade, velocidade e confiança não descartam, de forma alguma, divergências entre tradutores ou futuras melhorias pelo tradutor. Nisso devemos muito ao indeterminismo racionalista de Quine, particularmente à crítica de equivalência absoluta explicada pela 
situação comum na qual "um tradutor rejeita a tradução de outro [...]", ambos podendo estar corretos (Quine, 1975: 296-297). "Viabilidade" pode, nesse sentido, envolver a tradução para um público específico ou para atingir um dentre vários propósitos possíveis (um texto pode ser traduzido de muitos modos diferentes). Nossa definição permite, além disso, um grau de teorização direta dentro da prática de tradução, já que a geração de TTs alternativos necessariamente depende de uma série de hipóteses formuladas em algum nível (não importa quão desavisados deles possamos estar em muitos casos). A partir dessa perspectiva, a habilidade para teorizar é uma parte importante da competência tradutória, até mesmo se essa teorização nunca chegar a ser explícita. Nossa definição pretende dizer muito em muito poucas palavras. Deveria poder abranger as partes mais interessantes das muitas coisas que foram somadas aos modelos multicomponenciais vistos acima.

A definição, entretanto, permanece propositalmente minimalista; sua verdadeira virtude está no vasto número de coisas que não diz. Em uma leitura estrita, esse tipo de competência tradutória não levaria em conta os casos em que equivalência direta (one-to-one) é considerada necessária ou obrigatória. Por exemplo, considere um modelo que pega o TO faire un discours e que gera apenas o TT fazer um discurso (o exemplo é de Newmark, 1985). Tal modelo poderia ter muito a dizer sobre terminologia, ensino de línguas ou funcionamentos da mente em algumas formas de "tradução natural", mas não teria muito a ver com a competência tradutória específica designada por nossa definição (nós exigimos a geração de mais de uma tradução). A competência tradutória que nos interessa é, portanto, um processo de escolha entre alternativas viáveis. E isso pode ser potencialmente distinto da terminologia atual, do aprendizado de idioma e da ciência cognitiva naturalista, para nomear apenas algumas de nossas disciplinas vizinhas. Até certo ponto, é claro, a definição tem também certas virtudes políticas. Delimita uma área institucional para as coisas que deveríamos ensinar. 


\title{
Uma defesa do minimalismo
}

Nossa definição tem, assim, a virtude de suas limitações. Não diz que há um perfil profissional ideal; não finge que nenhuma outra grande competência jamais se misturará a ela. Pelo contrário, ficaríamos mais que confortáveis com a suposição de que tais misturas são cada vez mais a norma e que a competência tradutória pode, freqüentemente, ser um componente secundário na gama de habilidades necessárias a profissionais interculturais. Como bem coloca Gouadec, "tradutores precisam de uma multicompetência porque também devem trabalhar como documentalistas, terminologistas, escritores, etc., MAS, está na hora reconhecermos as distinções profissionais dessas atividades" (1991: 543). Aqui estamos propondo uma base precisamente para tal reconhecimento. Isso também é um pouco parecido com o que Don Kiraly diz quando distingue "competência tradutória" (a habilidade para produzir um texto aceitável, como acima) das esferas mais amplas da "competência do tradutor", o que

\begin{abstract}
envolve ligar várias comunidades novas tais como o grupo de usuários de vários idiomas, aqueles familiarizados com campos técnicos especializados, e usuários proficientes de ferramentas tradicionais e de novas tecnologias para fins de comunicação interlingual profissional. (2000: 13)
\end{abstract}

A profissão requer tais movimentos para e a partir de comunidades interculturais e técnicas; requer uma pletora de nomes novos para os novos trabalhos assim criados ("provedor de serviço de linguagem" é atualmente o mais apto). Contudo, nosso foco aqui é primeiramente aquilo que tradutores levam a essas comunidades, no seu tipo particular de competência. Ficamos, assim, com o termo "competência tradutória" e com nossa abordagem minimalista.

Quando nossa definição foi apresentada pela primeira vez à sociedade, numa conferência em Belgrado em 1989 (Pym, 1991), 
seguiram-se comentários quanto a três aspectos do treinamento do tradutor: a relação entre tradução e aprendizado de idioma, o papel da teoria no treinamento de tradutores e a relação entre instrutores e alunos de tradução. Esperava-se que uma definição minimalista pudesse ter conseqüências para, pelo menos, esses três aspectos, se não mais. Agora, uns 13 anos depois, tem-se que admitir que a tendência histórica esteve bem e verdadeiramente longe do tipo de definição que buscávamos. Parece, pois, mais apropriado reconsiderar esses pontos agora à vista de como os modelos multicomponenciais os trataram.

\section{A descontinuidade com o aprendizado de idiomas}

A abordagem minimalista deveria idealmente possibilitar uma distinção mais clara entre treinamento do tradutor e aprendizado de idioma. Este deveria ser, pelo menos até certo ponto, analítico, baseado em regras e orientado pela gramática, enquanto o treinamento dos tradutores deveria ser relativamente não-analítico, baseado em contexto e orientado por exemplos. Esse tipo de pensamento estava muito bem afinado com as políticas institucionais dos anos oitenta e início dos noventa, quando muitas escolas de tradução, pelo menos na Europa, estavam lutando para delimitar seu território com respeito aos bem estabelecidos departamentos de Línguas Modernas. Mary Snell-Hornby, por exemplo, estava conclamando escolas de tradução na Europa oriental a "cortar o cordão umbilical" com os departamentos de Línguas Modernas (1994: 433). Havia muito poucas vozes divergindo, embora Juliane House (1986: 182) insistisse corajosamente que adquirir competência comunicativa era o objetivo tanto da aula de idioma quanto do ensino de tradução.

Agora, uma vez que aquela batalha foi ganha (na Espanha, em 1991), muitas das escolas independentes de tradução tiveram que preencher os quatro ou cinco anos de seus programas. Como vimos, essas instituições tinham interesse direto na multicomponencialidade. De repente não havia urgência em separar tradução 
de bilingüismo, por exemplo, da mesma maneira que havia pouco interesse na idéia de comunidades profissionais separadas. Tudo podia ser mantido sob o mesmo teto; tudo faria parte da "competência tradutória”. Nesse sentido, importância estratégica deveria ser dada a tentativas de definir não apenas os modos especiais como a tradução deveria ser ensinada, mas também o modo como idiomas deveriam ser ensinados para tradutores (cf. a "competência pré-tradutória” esboçada em Presas, 1998). A descontinuidade antes buscada por virtualmente todos os estudiosos de tradução tornou-se agora uma linha bastante tênue e muito discutível.

\section{O papel da teoria}

A abordagem minimalista vê a tradução basicamente como um processo de produzir e selecionar hipóteses, e isto é, por si, um modo de teorização constante. Se pensarmos bem, o modelo reivindica que os tradutores teorizam sempre que traduzem; a teorização é uma parte importante da prática tradutória. O modelo também insinua que abordagens completas de tradução podem ser relacionadas ao ato de traduzir de dois modos: elas podem ajudar os tradutores a produzir mais alternativas do que de outra forma teriam pensado, e/ou podem ajudá-los a eliminar possíveis alternativas. Teorias seriam assim produtivas e/ou redutivas, e ambos os tipos são obviamente necessários. Abordagens desconstrutivistas são, por exemplo, soberbamente produtivas, mas raramente redutivas; a Skopostheorie em seu mais puro estado é eminentemente redutiva, mas não muito produtiva, e assim por diante. Isso nos dá um grupo de razões muito práticas para achar virtudes e faltas em teorias, e para ensinar teorias de tradução como tal.

Por outro lado, os modelos multicomponenciais parecem encontrar pouco lugar para teoria. Apenas Kautz (2000) explicitamente menciona "teoria da tradução e métodos" como um componente. Outros, em particular Hurtado (1999), estão mais preocupados em distinguir entre teoria e competência, no final das contas para substituir teorias de tradução consagradas por uma lista de 
“objetivos de aprendizagem" específicos e seqüenciais. Partindo dessa perspectiva, a tendência global tem ido em direção à competência como um complexo de vários tipos de conhecimento declarativo e de habilidades técnicas. E é precisamente esse o tipo de conhecimento que a teorização está destinada a desafiar.

\section{Relações estudante-instrutor}

Uma definição minimalista de competência tradutória implicitamente recusa os modelos de verdade que estão por trás das abordagens da tradução como equivalência. Ao fazer isso, também contesta o papel autoritário que tal modelo reserva ao professor de tradução. Isso significa que, embora os professores tenham certamente todo direito para apresentar seus próprio TTs e avaliar o TTs divergentes de alunos individuais, o verdadeiro treinamento de tradutores não deveria refletir o individualismo de tais procedimentos de avaliação. É verdade que tradutores individuais têm de ser capazes de gerar alternativas e de decidir entre elas, mas raramente é verdade que devam fazer isso completamente sozinhos. $\mathrm{Na}$ situação de treinamento, o uso implícito de informantes no recurso a dicionários e à Internet é facilmente estendido ao uso de estudantes de intercâmbio e de especialistas acadêmicos. No contexto profissional, tais modos de interação serão estendidos então a redes de contatos, clientes e colaboradores. Realmente, o impacto principal da tecnologia nesse campo é estender o alcance de tais redes, ampliando o momento produtivo e obscurecendo freqüentemente as necessidades de redução. A habilidade para usar e negociar com uma pluralidade de proposições e opiniões é, assim, uma parte crescente da competência tradutória. Não deveria ser marginalizada por preconceito individualista, exigências de exames ou pressuposições de metodologias de pesquisa.

A ênfase na interação como parte da competência tradutória deveria, por sua vez, influenciar princípios gerais como a normalidade de grupos de estudante extremamente heterogêneos, a necessidade de se usar textos "autênticos" ou mal escritos como base 
para discussão e debate, e o desejo de envolver os estudantes em um grande número de atividades profissionais ou semiprofissionais. Nesses pontos, nossa abordagem minimalista está em acordo fundamental com muitos dos conceitos multicomponenciais.

\section{Solucionando o problema}

Voltemos agora ao nosso problema original. Fatores históricos exigem que ensinemos a nossos alunos uma grande variedade de ferramentas eletrônicas, e não estamos certos de que essas coisas devam fazer parte de nosso conceito de competência tradutória. Como deveríamos agora responder a nossos alunos?

A resposta mais fácil seria talvez a multicomponencial: vocês todos têm que saber todas essas coisas; do contrário, não acharão um trabalho, e é isso. Contudo, a tecnologia sempre estará um ou dois passos à frente de qualquer lista multicomponencial, e a história de tais conceitos corresponde a um dos mais confusos e discrepantes balaios de gato dos Estudos da Tradução contemporâneos. Fica-se tentado a lavar as mãos quanto ao assunto, como realmente foi a primeira resposta de Wilss lá em 1976.

Uma resposta melhor deveria vir de uma definição minimalista, negociando-se alguns paradoxos. Como vimos, a abordagem minimalista é projetada para elevar a teorização acima do conhecimento declarativo e das habilidades técnicas, de acordo com uma pedagogia altamente interativa e experiencial. E ainda, na superfície, as habilidades associadas a ferramentas eletrônicas são de um tipo altamente declarativo e técnico. Na base, sabe-se ou não como usar uma determinada ferramenta; move-se de objetivos mais simples para outros mais complexos; essas habilidades raramente envolvem a produção e seleção de alternativas. Como professor de teoria, interessado em trabalhar com alunos de teoria, sou levado a admitir que meus alunos críticos têm bastante razão nesse caso. A maioria dessas habilidades eletrônicas não é vista prazerosamente como parte de compe- 
tência tradutória; elas não deveriam ser confundidas com o propósito principal de nosso ensino. Elas deveriam, certamente, estar lá, na sala de aula, mas não desfrutando lugar de honra.

$\mathrm{O}$ que isso significa em termos práticos? Basicamente, isso sugere que nós não devemos perder vista nossos objetivos como instrutores de tradutores. A maioria das ferramentas eletrônicas consiste, simplesmente, em técnicas que aceleram e ampliam a produção de TTs alternativos (cf. o que pode ser feito com buscas na Web); outras são extensões que favorecem a eliminação autorizada de alternativas (cf. as vantagens básicas de memórias de tradução e glossários de todos os tipos). Os tradutores produzem alternativas e selecionam dentre elas; as várias novas tecnologias não alteram essas tarefas, elas simplesmente ampliam-lhes o alcance, lidando com mais do mundo em menos tempo. Nesse sentido, uma visão minimalista de competência deveria ajudar a nos manter conscientes dos fins de nossas tarefas, sem nos perdermos nos meios.

Ao mesmo tempo, uma abordagem minimalista pode sustentar uma abordagem crítica a essas tarefas e tecnologias que realmente confundem os meios com os fins. Por exemplo, a abundância pósmoderna de informação torna fácil a produção de TTs alternativos, o que significa que mais ênfase tem que ser dada à eliminação de possíveis TTs. Devemos ensinar aos estudantes a desconfiar de sites da Web, por exemplo, ou pelo menos a os avaliar com suspeita. Por outro lado, o uso de memórias de tradução facilita a repetição irrefletida de TTs anteriores, de forma que o que falta em tais modos de trabalho é a produção ativa de hipóteses; claramente, o lado que nossa pedagogia deve então enfatizar. Mais importante, o uso de sites da Web, de memórias e do resto impõe uma mediação volumosa entre o tradutor e a figura do leitor alvo. Aquela tecnologia nos convida a esquecer que determinados TTs são melhores que outros porque são destinados para alcançar um certo propósito, em determinado tempo e espaço, para um certo usuário final. Elas nos convidam a esquecer que nossas tarefas básicas envolvem a comunicação entre humanos, e só então a manipulação da mediação eletrônica. 
Um conceito minimalista de competência deveria ajudar a manter tais objetivos claramente em mente. Por outro lado, um modelo multicomponencial tende a aceitar a complexidade sem distinguir criticamente entre os meios e os fins. E isso, com todo devido respeito e compreensão, é uma receita para perdição.

Tradução de Adauto Villela

\section{Notas}

1. Todas as traduções são nossas.

2. Isso é porque os modelos inicialmente precedem pesquisas empíricas, oferecendo virtudes políticas cuja única falsificação significativa está na história política. $\mathrm{O}$ corpo de descobertas empíricas está indubitavelmente crescendo, embora freqüentemente de um modo que oferece pouco mais que autojustificação. O que descobrimos cada vez mais é que as ferramentas de pesquisa condicionam os tipos de perguntas que fazemos sobre a competência tradutória. Por exemplo, uma vez que a maioria dos pesquisadores empíricos observa tradutores individuais que trabalham sós, eles tendem a ignorar as habilidades profissionais mais periféricas e a crescente importância do trabalho em equipe (que deveria se estender até o gerenciamento de projetos). Formula-se daí uma noção de competência tradutória adequada a salas de aula onde os alunos traduzem textos sozinhos, seja para a L2 (cf. Krings, 1986) ou a partir da L2 (cf. Campbell, 1992, 2000). A idéia de tradução multidirecional de grupo não é admitida como objeto de pesquisa, simplesmente porque aulas tradicionais de tradução não são projetadas desse modo. De maneira semelhante, se nós tivermos acesso a um corpus de linguagem tradutória e não-tradutória, teremos mais probabilidade de perguntar a respeito da variação relativa nas produções de tradutores, e isso se tornará então um componente daquilo que concerne à competência tradutória (como tem sido o caso em anos recentes). $\mathrm{Ou}$, novamente, se nós vamos usar protocolos de descrição oral de processos mentais, nosso modelo de competência tenderá a contar e categorizar os passos tomados para resolver problemas (cf. Lörscher 1991). Se usarmos o Translog, perguntaremos sobre o gerenciamento conceitual do tempo. O problema aqui é que, 
ao tentarem ser abrangentes em campos onde disciplinas de pesquisa estão mais bem estabelecidas, poucos modelos captam com sucesso áreas nas quais as mudanças

mais importantes estão acontecendo (trabalho em equipe, memórias de tradução e o uso de recursos da Internet). Ao aplicar uma ciência inerentemente conservadora, eles, no final das contas, hipostasiam a profissão.

\section{Bibliografia}

BACHMAN, Lyle F. (1990) Fundamental Considerations in Language Testing, Oxford: Oxford University Press.

BALLARD, Michel (1984) "La traduction relève-t-elle d'un pédagogie?", Michel Ballard (ed) La traduction: de la théorie à la pratique, Lille: Université de Lille III.

BAUSCH, K. R. (1977) “Zur Übertragbarkeit der Übersetzung als Fertigkeit auf die Übersetzung als Übungsform”, Die Neueren Sprachen 26, 517-535.

BEEBY, Allison (1996) Teaching Translation from Spanish to English, Ottawa: Ottawa University Press.

BEEBY, Allison (2000) "Choosing an Empirical-Experimental Model for Investigating Translation Competence: The PACTE Model”, Maeve Olohan (ed.) Intercultural Faultlines. Research Models in Translation Studies I. Textual and Cognitive Aspects, Manchester: St Jerome, 43-55.

BELL, Roger T. (1991) Translation and Translating. Theory and Practice. London and New York: Longman.

CAMPBELL, Stuart (1991) "Towards a Model of Translation Competence", Meta $36(2 / 3), 329-343$. 
CAMPBELL, Stuart (2000) "Choice Network Analysis in Translation Research", Maeve.

OLOHAN (ed.) Intercultural Faultlines. Research Models in Translation Studies I. Textual and Cognitive Aspects, Manchester: St Jerome, 29-42.

CHOMSKY, Noam (1965) Aspects of the Theory of Syntax, Cambridge Mass.: MIT Press.

FRASER, Janet (2000) "The Broader View: How Freelance Translators Define Translation Competence", Christina Schäffner \& Beverly Adab (eds) Developing Translation Competence, Amsterdam \& Philadelphia: Benjamins, 51-62.

GOUADEC, Daniel (1991) “Autrement dire... pour une redéfinition des stratégies de formation des traducteurs", Meta 36(4): 543-557.

HARRIS, Brian (1977) “The Importance of Natural Translation", Working Papers in Bilingualism 12, 96-114.

HARRIS, Brian \& Bianca SHERWOOD (1978) “Translating as an Innate Skill”, David Gerver \& H.

WALLACE, Sinaiko (eds) Language, Interpretation and Communication, New York \& London: Plenum, 155-170.

HATIM, Basil \& Ian Mason (1997) The Translator as Communicator, London \& New York: Routledge.

HEWSON, Lance (1995) "Detecting Cultural Shifts: Some Notes on Translation Assessment", Ian Mason \& Christine Pagnoulle (eds) Cross-Words. Issues and Debates in Literary and Non-Literary Translating, Liège: University of Liège, 101-108.

HOLZ-MÄNTTÄRI, Justa (1984) Translatorisches Handeln. Theorie und Methode, Helsinki: Academia Scientiarum Fennica. 
HOUSE, Juliane (1986) “Acquiring Translational Competence in Interaction”, Juliane House \& Shoshana Blum-Kulka (eds) Interlingual and Intercultural Communication: Discourse and Cognition in Translation and Second Language Acquisition Studies, Tübingen: Narr, 179-191.

HURTADO ALBIR, Amparo (1993) "Un nuevo enfoque de la didáctica de la traducción. Metodología y diseño curricular", Les Langues étrangères dans l'Europe de l'Acte Unique, Bellaterra: ICE de la Universitat Autònoma de Barcelona.

HURTADO ALBIR, Amparo (1996) "La enseñanza de la traducción directa 'general'. Objetivos de aprendizaje y metodología”, Amparo Hurtado Albir (ed.) La enseñanza de la traducción, Castelló: Publicacions de la Universitat Jaume I. 31-55.

HURTADO ALBIR, Amparo (dir.) (1999) Enseñar a traducir: metodología en la formación de traductores e intérpretes, Madrid: Edelsa.

KAUTZ, Ulrich (2000) Handbuch Didaktik des Übersetzens und Dolmetschens, München: Iudicum, Goethe-Institut.

KIRALY, Don (2000) A Social Constructivist Approach to Translator Education. Empowerment from Theory to Practice, Manchester: St Jerome.

KOLLER, Werner (1979) Einführung in die Übersetzungswissenschaft, Heidelberg: Quelle \& Meyer.

KOLLER, Werner (1992) Einführung in die Übersetzungswissenschaft, Völlig neu bearbeitete Auflage, Heidelberg, Wiesbaden: Quelle \& Meyer.

KRINGS, Hans P. (1986) Was in den Köpfen von Übersetzern vorgeht, Tübingen: Gunter Narr.

LEE-JAHNKE, Hannelore (1997) "Voraussetzungen für eine optimale Übersetzerausbildung heute", Eberhard Fleischmann, Wladimir Kutz, Peter A. Schmitt (eds) Translationsdidaktik. Grundfragen der Übersetzungswissenschaft, Tübingen: Gunter Narr, 178-183. 
LÖRSCHER, Wolfgang (1991) Translation Performance, Translation Process, and Translation Strategies. A Psycholinguistic Investigation. Tübingen: Gunter Narr.

LÖRSCHER, Wolfgang (1996) "A Psycholinguistic Analysis of Translation Processes", Meta 41(1): 26-32.

MAYORAL, Roberto (2001) Aspectos epistemológicos de la traducción, Castelló: Publicacions de la Universitat Jaume I.

NEWMARK, Peter (1985) “Literal Translation”, Parallèles: Cahiers de l'Ecole de Traduction de Genève 7.

NORD, Christiane (1991) Textanalyse und Übersetzen, Heidelberg: Julius Groos.

PRESAS, Marisa (1997) "Problembestimmung und Problemlösung als Komponenten der Übersetzungskompetenz", Eberhard Fleischmann, Wladimir Kutz, Peter A. Schmitt (eds) Translationsdidaktik. Grundfragen der Übersetzungswissenschaft, Tübingen: Gunter Narr, 587-592.

PRESAS, Marisa (1998) "Los componentes de la competencia pretraductora en el marco del diseño curricular”. Isabel García Izquierdo \& Joan Verdegal (eds) Los estudios de la traducción: un reto didáctico, Castelló: Publicacions de la Universitat Jaume I, 131-134.

PYM, Anthony (1991) "A Definition of Translational Competence, Applied to the Teaching of Translation", Mladen Jovanovic (ed.) Translation: A Creative Profession: $12^{\text {th }}$ World Congress of FIT. Proceedings, Belgrade: Prevodilac, 541-546.

PYM, Anthony (1992) Epistemological Problems in Translation and its Teaching, Calaceite: Caminade.

QUINE, Willard Van Orman (1975) "Reply to Harman”, Donald Davidson \& J. Hintilla (eds) Words and Objections: Essays on the Work of W. V. Quine, Revised Edition, Dordrecht \& Boston: Reidel, 267-269.

RISKU, Hanna (1998) Translatorische Kompetenz. Kognitive Grundlegen des Übersetzens als Expertentätigkeit, Tübingen: Stauffenburg. 
SAUSSURE, Ferdinand de (1974) Cours de linguistique général, first published 1916, ed. C. Bally \& A. Sechehaye, trans. W. Baskin as Course in General Linguistics. Glasgow: Fontana Collins.

SCHÄFFNER, Christina \& Beverly Adab (2000) "Developing Translation Competence: Introduction", Christina Schäffner \& Beverly Adab (eds) Developing Translation Competence, Amsterdam \& Philadelphia: Benjamins, vii-xvi.

SHREVE, Gregory M. (1997) "Cognition and the Evolution of Translation Competence", Joseph H. Danks et al. (eds) Cognitive Processes in Translation and Interpreting, Thousand Oaks, London, New Delhi: Sage.

SNELL-HORNBY, Mary (1994) in Doina Motas, Jennifer Williams, Mary SnellHornby, "New Translation Departments - Challenges of the Future", Mary SnellHornby, Franz Pöchhacker \& Klaus Kaindl (eds) Translation Studies, An Interdiscipline, Amsterdam \& Philadelphia: Benjamins, 431-434.

TOURY, Gideon (1984) “The Notion of 'Native Translator' and Translation Teaching”, Wolfram Wilss \& Gisela Thome (eds) Die Theorie des Übersetzens und ihr Aufschlusswert für dir Übersetzungs- und Dolmetschdidaktik, Tübingen: Narr, 186-195.

TOURY, Gideon (1986) "Natural Translation and the Making of a Native Translator", TextconText 1, 11-29.

TOURY, Gideon (1995) Descriptive Translation Studies and beyond, Amsterdam \& Philadelphia: Benjamins.

WADDINGTON, Christopher (2000) Estudio comparativo de diferentes métodos de evaluación de traducción general (inglés-español), Madrid: Publicaciones de la Universidad Pontificia Comillas.

WILSS, Wolfram (1976) "Perspectives and Limitations of a Didactic Framework for the Teaching of Translation", Richard W. Brislin (ed.) Translation. Applications and Research, New York: Gardner Press. 117-137.

WILSS, Wolfram (1982) The Science of Translation. Problems and Methods, Tübingen: Gunter Narr. 
WILSS, Wolfram (1988) Kognition und Übersetzen, Tübingen: Niemeyer.

WILSS, Wolfram (1992) Übersetzungsfertigkeit, Annäherungen an einen komplexen übersetzungspraktischen Begriff, Tübingen: Gunter Narr.

WILSS, Wolfram (1996) Übersetzungsunterricht. Eine Einführung, Tübingen: Gunter Narr. 